\title{
Response to the Comment on "A New Taxonomy for Postactivation Potentiation in Sport"
}

We thank Dr Smith and Professor MacIntosh for the opportunity to further discuss the implications of the new proposed taxonomy. In their letter, ${ }^{1}$ they claim that the definition they propose is in contrast with that cited in our article ${ }^{2}$ and argue that, while their definition does not stipulate a mechanism, our definition does so. Honestly, we find it challenging to distinguish between the 2 definitions. ${ }^{1,2}$ When comparing the terminology, we see quite similar nomenclature and no mechanisms proposed. Furthermore, our definition does not differ substantially from prior classical definitions. ${ }^{3}$

Smith and MacIntosh state: "This is an important point because Boullosa et al justify their commentary based on assumed mechanisms." However, it has been ubiquitously agreed since the pioneering works in the 80 s that the mechanisms for postactivation potentiation (PAP) are well established. In fact, Professor MacIntosh's own impressive work has helped to define these mechanisms. ${ }^{4,5}$ Hence, the literature has consistently agreed upon the mechanisms of PAP over the last 30 years.

On another point, Smith and MacIntosh state: "Twitch potentiation dissipates over the $\sim 6$-minute period immediately after a conditioning contraction. ${ }^{5}$ For this reason, any enhancement of performance or contractile response outside of this time cannot be attributed to PAP." However, the time course of PAP is not as static as Smith and MacIntosh propose, with examples in the literature of PAP recorded $>6$ minutes after the conditioning activity. ${ }^{2,6}$

Smith and MacIntosh continue: "However, it is important to realize that PAP is not limited to isometric twitch contractions and that PAP of other contraction types could, theoretically, contribute to PAPE if the effects coincide temporally."1 In our article, we agreed with this statement. ${ }^{2}$ Our contention was that voluntary contractions have a lower signal-to-noise ratio, making it more difficult to detect voluntary changes associated with PAP.

It is interesting that Smith and MacIntosh indicate that there should only be 2 descriptors (PAP and postactivation performance enhancement [PAPE]) and that there is no possibility for alternative terminologies. The proposed taxonomy highlights the conditioning activity, testing activity and population, factors causally related to the onset, and magnitude of potentiation effects. For instance, the rationale for a lack of increased voluntary performance would be more apparent in the case of the following descriptor: "Post lowintensity squats jump potentiation in sedentary males." In this case, the conditioning activity and population are less likely to induce and experience potentiation, respectively. There is no reason that more general descriptors such as PAP and PAPE cannot coexist with our proposed taxonomy, as we clearly stated in our article. ${ }^{2}$

Daniel Boullosa (daniel.boullosa@gmail.com), Federal University of Mato Grosso do Sul, Brazil

Marco Beato, University of Suffolk, United Kingdom

Antonio Dello Iacono, University of the West of Scotland, United Kingdom

Francisco Cuenca-Fernández, University of Granada, Spain

Kenji Doma, James Cook University, Australia

Moritz Schumann, German Sport University Cologne, Germany

Alessandro Moura Zagatto, São Paulo State University, Brazil

Irineu Loturco, Nucleus of High Performance in Sport, Brazil; University of South Wales, United Kingdom; and Federal

University of São Paulo, Brazil

David G. Behm, Memorial University of Newfoundland, Canada

\section{References}

1. Smith IC, MacIntosh BR. A comment on "A new taxonomy for postactivation potentiation in sport." Int J Sports Physiol Perform. 2021; 16(2):163. doi:10.1123/ijspp.2020-0586

2. Boullosa D, Beato M, Dello Iacono A, et al. A new taxonomy for postactivation potentiation in sport. Int J Sports Physiol Perform. 2020;15(8):1197-1200. PubMed ID: 32820135 doi:10.1123/ijspp .2020-0350

3. Sale DG. Postactivation potentiation: role in human performance. Exerc Sport Sci Rev. 2002;30(3):138-143. PubMed ID: 12150573 doi:10.1097/00003677-200207000-00008

4. Rassier DE, MacIntosh BR. Coexistence of potentiation and fatigue in skeletal muscle. Braz J Med Biol Res. 2000;33(5):499-508. PubMed ID: 10775880 doi:10.1590/S0100-879X2000000500003

5. MacIntosh BR, Robillard ME, Tomaras EK. Should postactivation potentiation be the goal of your warm-up? Appl Physiol Nutr Metab. 2012;37(3):546-550. PubMed ID: 22515147 doi:10.1139/h2012-016

6. Vandervoort AA, Quinlin J, McComas AJ. Twitch potentiation after voluntary contraction. Exp Neurol. 1983;81(1):141-152. PubMed ID: 6861942 doi:10.1016/0014-4886(83)90163-2 